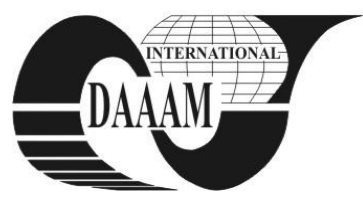

Annals of DAAAM for 2011 \& Proceedings of the 22nd International DAAAM Symposium, Volume 22, No. 1, ISSN 1726-9679 ISBN 978-3-901509-83-4, Editor B. Katalinic, Published by DAAAM International, Vienna, Austria, EU, 2011 Make Harmony between Technology and Nature, and Your Mind will Fly Free as a Bird Annals \& Proceedings of DAAAM International 2011

\title{
ASSEMBLE-DISASSEMBLE CELL MATERIAL FLOW MANAGEMENT
}

\section{COTET, C[ostel] E[mil]; POPA, C[icerone] L[aurentiu]; CHISCOP, F[lorina]; PARPALA, L[idia] F[lorentina]; DRAGOI, G[eorge] \& ROSU, S[ebastian] M[arius]}

\begin{abstract}
We propose here an optimizing algorithm available for diffused assemble disassemble systems illustrated by a case study. This optimizing algorithm is meant to improve the productivity rates of the assembly disassemble process. We perform this optimization using Witness software by analyzing the results of the material flow simulation and identifying the points where the entire flow is strangled generating blockage at the work points of the system. We propose a solution for this problem elimination, and we perform a second simulation to validate that solution. The productivity improvement is significant, validating our algorithm
\end{abstract}

Key words: assembly, disassembly, productivity, simulation

\section{INTRODUCTION}

We will first present here an overview description of the manufacturing system under study (the fixing devices assemble and disassemble flexible cell), some major techniques used in flexible cells model building and then focusing on its operational flow. We then describe the construction, verification, and validation of the simulation models. In conclusion, we present the results obtained from statistical analyses of model output, the use of these results in identifying the material flow concentrator, and the new indicated cell design directed to increase production rates (Cotet, 2003).

We had applied our algorithm on diffused manufacturing systems where are several work points of the same importance in the system. Discrete material flow management optimization, the use of search methods to find input parameter settings that improve selected output measures of a simulated system, has developed steadily in recent years (Dhouib \& al., 2009). These developments would probably not have taken place without the application of heuristic search algorithms, such as genetic algorithms. Although they lack desirable convergence properties, heuristic search algorithms have provided good, reasonably fast, results on a wide variety of problems. Breadth and speed are critical (Wang \& Ingham, 2008). Even though a number of provably such convergent algorithms have been developed, they may work well on only a subset of problems as one can see on our case study (Cotet \& Dragoi, 2008).

\section{SYSTEM OVERVIEW}

In order to test these optimization techniques our faculty had initiated a research partnership with industrial partners, analyzing several case studies on machine tool integrated production flow designed and realized in Romania, and we had been asked to make some changes in flexible cells architectures in order to better adapt those systems at the manufactured parts categories (Gill, 2008).

We had tested those techniques permitting us to improve the system architecture, based on the simulations performed in the PREMINV laboratories of the faculty.

The lab provides a discrete material flow simulation for the parts that are machined in manufacturing systems.

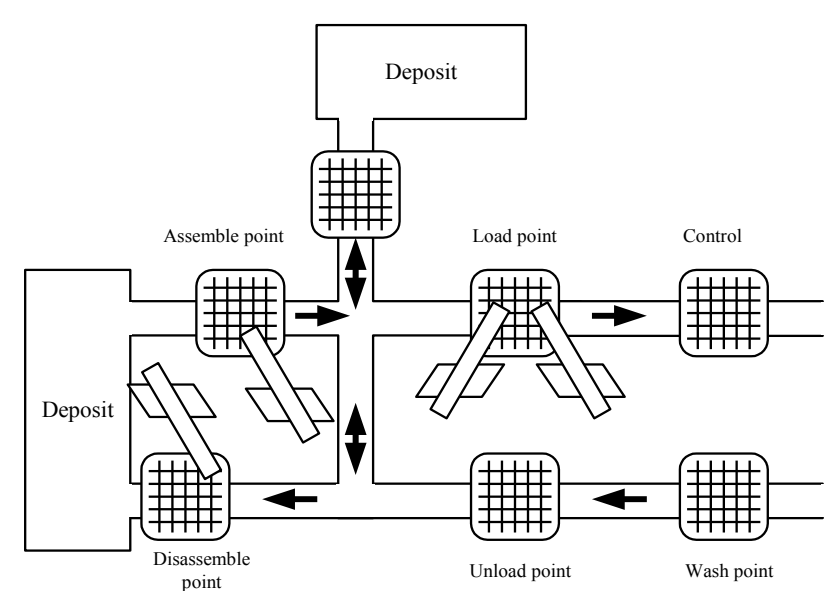

Fig.1. View of the assemble and disassemble cell

In order to improve the process, one can perform a discrete event simulation using WITNESS that provided a realistic model of the manufacturing process in the machine tool field and allowed to quickly and inexpensively evaluate a wide range of alternatives. In this paper we present a case study on a cell used to assemble and disassemble fixing devices (figure 1).

\section{OPTIMIZING THE CELL}

The simulations of the manufacturing processes, tools \& parts circulation are giving us the possibility to identify the critical point in the material flow for a specific product gamma manufactured in the system. Based on those simulations we are using the diagnosis reports to make the necessary corrections in order to eliminate the flow concentrator by adjusting the system architecture.

In order to make the necessary correspondence between the elements of the assemble-disassemble industrial flexible cell and our Witness conceptual model we had used a table (table 1). In this table the transport modules (1 to 7) are assimilated to conveyors.

\begin{tabular}{|l|l|}
\hline Flexible cell & Witness model \\
\hline Transport module 1 & tr01 \\
\hline Transport module 2 & tr02 \\
\hline Transport module 3 & tr03 \\
\hline Transport module 4 & tr04 \\
\hline Transport module 5 & tr05 \\
\hline Assemble point & asambl \\
\hline Part loading point & incarc \\
\hline control & control \\
\hline Disassemble point & dezasmb \\
\hline Part unloading point & descarc \\
\hline Washing point & spalare \\
\hline Transport module 7 & tr07 \\
\hline
\end{tabular}

Tab1. Real and modeled elements correspondence 


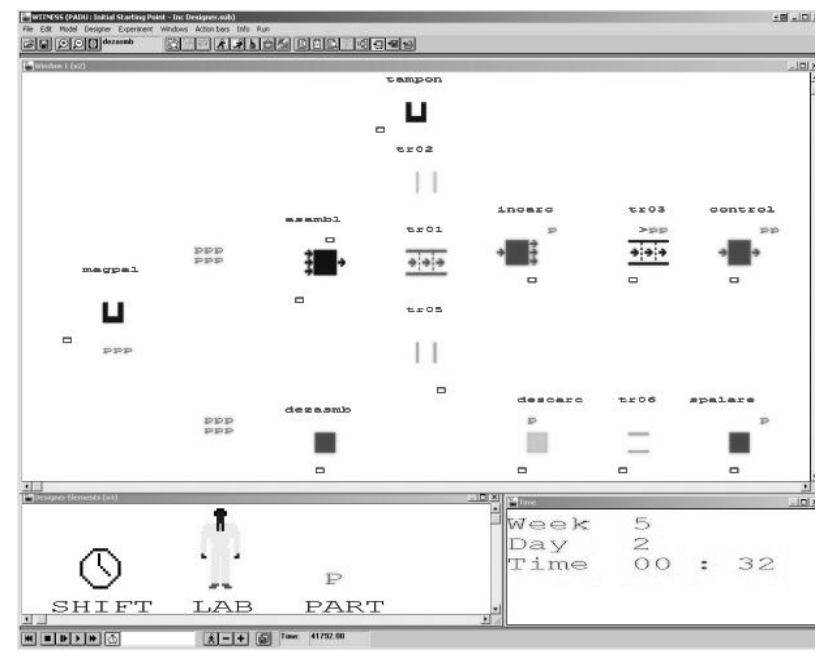

Fig.2. Model of the initial assemble and disassemble cell

We propose here a comparative analysis illustrating the productivity improvement using material flow simulation for an industrial case study for a specific assemble disassemble cell. First we present the initial model of the cell (figure 2), the material flow simulation results and our conclusions on the flow concentrator based on those simulations. After identifying the flow concentrator we will focus on our system architecture modifications necessary in order to improve this critical point flow transit without generate another concentrator in the flow. In the last part of the paper we will perform a new simulation of a manufacturing cycle on our modified system in order to validate this solution and we will quantify the productivity improvement.

The results of this first simulation for a time of 7 weeks, 3 days, 17 hours, 42 minutes show that a number of 2500 parts were processed after 7 weeks, 3 days, 17 hours, 42 minutes.

Analyzing all the reports we have made the presumption that the transport module tr05 can be identified as the material flow concentrator. In order to validate this presumption we had studied the report for this transport module.

As we can see studying the reports for all the work points in the system as well as for the transport module tr05 who is working only $19 \%$ of the entire time this point has the worst report an represents the flow concentrator.

Following the optimization techniques presented before the solution proposed by us for a better management of this flow is to double the capacity of the tr05. In the conceptual model the meaning of this solution was the adding of an extra conveyor tr07 with the same characteristics as tr05 (figure 3 ).

For this new model if we perform a simulation for the same time of 7 weeks, 3 days, 17 hours, 42 minutes, and with the same characteristics of the work points the two transport modules tr05 and tr07 these points will be working $67 \%$ and $62 \%$ of the time and the productivity will increase from 2500 to 4100 parts processed (figure 4).

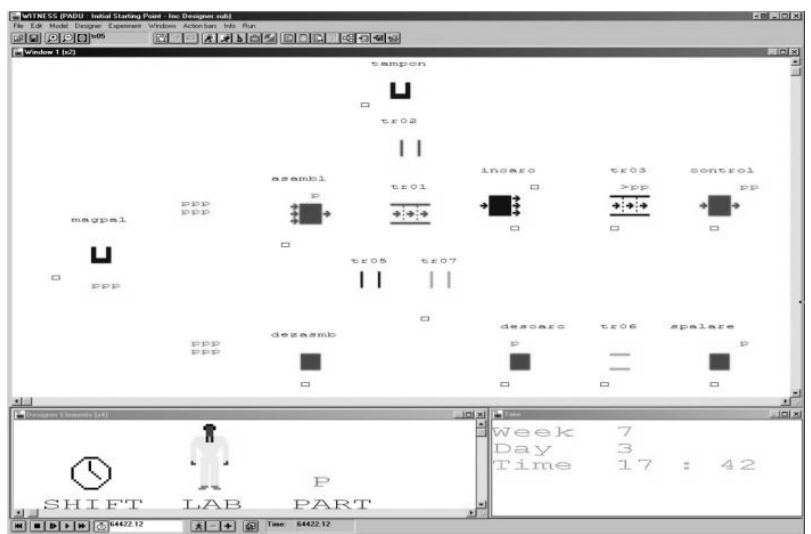

Fig.3. Model of the optimized assemble and disassemble cell

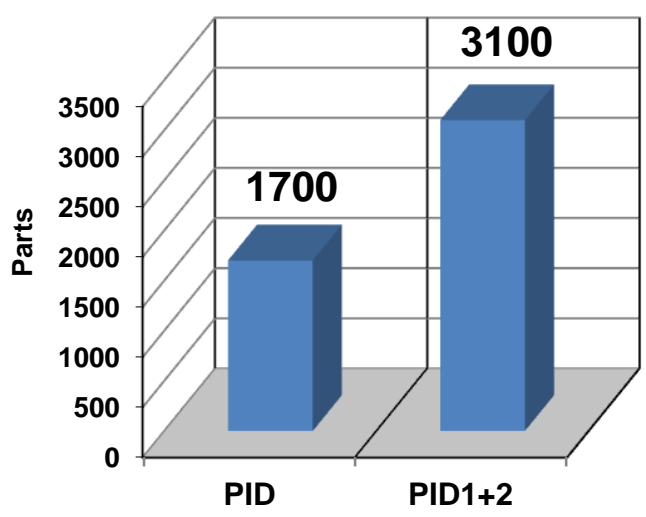

Fig.4. Productivity report before and after optimization

\section{CONCLUSION}

We had applied in this paper a set of simulation techniques used to optimize the assemble disassemble architectures by improving the discrete material flow management. We had analyzed the results of the material flow simulation and we had identified the flow concentrator.

We had proposed an architecture modification as a solution for this problem. We had performed a second simulation to validate that solution and we had obtained an increased productivity.

\section{ACKNOWLEDGEMENTS}

This work was supported by CNCSIS-UEFISCSU, project number PN-II RU 233/2010, project title: "Assembly/Disassembly Process Modeling", project type: "Research projects for stimulation of the founding/forming of young independent research teams".

\section{REFERENCES}

Cotet. C.E, (2003) - Optimizing concentrate and diffused FMS systems architecture by material flow simulation techniques, The 14th INTERNATIONAL DAAAM SYMPOSIUM, "Intelligent Manufacturing \& Automation: Focus on Reconstruction and Development", 22-25th October 2003, pag. 103-104, ISBN 3-901509-34-8, ISSN 1726-9679

Cotet C. E., Dragoi G., Abaza B.F., (2008) - Groundhog day versus butterfly effect revisited in discrete material flow management, in the Annals of DAAAM for 2007 \& Proceedings of the 19th INTERNATIONAL DAAAM SYMPOSIUM "Intelligent Manufacturing \& Automation: Focus on Next Generation of Intelligent Systems and Solutions", 22-25th October 2008, Tarnava, Slovacia, pp. 0315-0316, ISSN 1726-9679, ISBN 3-901509-58-5, published by DAAAM International Vienna, Austria, edited by Branko Katalinic, 2008

Dhouib, K., Gharbi, A. \& Ayed, S. (2009). Simulation based throughput assessment of non-homogeneous transfer lines, In: International Journal of Simulation Modelling IJSIMM, Volume 8, no. 1, March 2009, pp.5-15, ISSN 1726-4529, Vienna

Gill, A. (2008). Identifying potential bottlenecks through activity under-utilization cost, In: International Journal of Simulation Modelling IJSIMM, Volume 7, no. 4, December 2008, pp.165-175, ISSN 1726-4529, Vienna

Wang, Q., Ingham, N. (2008). A discrete event modelling approach for supply chain simulation, In: International Journal of Simulation Modelling IJSIMM, Volume 7, no. 3, September 2008, pp.124-134, ISSN 1726-4529, Vienna 